\title{
Selective serotonin reuptake inhibitors in pediatric depression: is the balance between benefits and risks favorable?
}

\author{
Christopher J. Kratochvil \\ University of Nebraska Medical Center, ckratoch@unmc.edu \\ Benedetto Vitiello \\ National Institute of Mental Health \\ John Walkup \\ Johns Hopkins University \\ Graham Emslie \\ University of Texas Southwestern \\ Bruce D. Waslick \\ Baystate Medical Center
}

See next page for additional authors

Tell us how you used this information in this short survey.

Follow this and additional works at: https://digitalcommons.unmc.edu/com_psych_articles

Part of the Psychiatry Commons

\section{Recommended Citation}

Kratochvil, Christopher J.; Vitiello, Benedetto; Walkup, John; Emslie, Graham; Waslick, Bruce D.; Weller, Elizabeth B.; Burke, William J.; and March, John S., "Selective serotonin reuptake inhibitors in pediatric depression: is the balance between benefits and risks favorable?" (2006). Journal Articles: Psychiatry. 14. https://digitalcommons.unmc.edu/com_psych_articles/14

This Article is brought to you for free and open access by the Psychiatry at DigitalCommons@UNMC. It has been accepted for inclusion in Journal Articles: Psychiatry by an authorized administrator of DigitalCommons@UNMC. For more information, please contact digitalcommons@unmc.edu. 


\section{Authors}

Christopher J. Kratochvil, Benedetto Vitiello, John Walkup, Graham Emslie, Bruce D. Waslick, Elizabeth B. Weller, William J. Burke, and John S. March 


\title{
Selective Serotonin Reuptake Inhibitors in Pediatric Depression: Is the Balance Between Benefits and Risks Favorable?
}

\author{
Christopher J. Kratochvil, M.D., ${ }^{1}$ Benedetto Vitiello, M.D., ${ }^{2}$ John Walkup, M.D., ${ }^{3}$ \\ Graham Emslie, M.D., ${ }^{4}$ Bruce D. Waslick, M.D., ${ }^{5}$ Elizabeth B. Weller, M.D., ${ }^{6}$ \\ William J. Burke, M.D., ${ }^{1}$ and John S. March, M.D.7
}

\begin{abstract}
Recent controversies surrounding the use of selective serotonin reuptake inhibitors (SSRIs) have highlighted the need to reassess potential benefits, as well as potential risks of this class of medications in the treatment of pediatric depression. The recent availability of data from metaanalyses of published and unpublished antidepressant trials, epidemiological studies, and the Treatment for Adolescents with Depression Study (TADS) has facilitated a reanalysis of this risk/benefit relationship. Despite reviewing similar data, various regulatory agencies have arrived at rather disparate conclusions regarding the data, resulting in continued controversy. Although all groups appear to agree that careful assessment, education regarding risks, and closer monitoring are essential for SSRIs, only the U.S. Food and Drug Administration (FDA) and the U.K. Medicine and Health Care Products Regulatory Agency maintain that an acceptable risk/benefit relationship exists for fluoxetine. The European Medicines Agency concluded that the SSRIs should not be used in the treatment of depression in children and adolescents. The authors of this review have taken into consideration many of these same data and offer a critical discussion of the pros and cons of SSRIs in pediatric depression. The authors have concluded that SSRIs-in particular, fluoxetine-do have a role in the treatment of pediatric depression.
\end{abstract}

\section{INTRODUCTION}

$\mathbf{T}$ HE USE OF THE SELECTIVE serotonin reuptake inhibitors (SSRIs) has grown significantly in the treatment of pediatric major depressive disorder (MDD), owing, in part, to efficacy data in adults, ease of dosing, and perception of good tolerability and safety in overdose. However, concerns have arisen intermittently over the past decade regarding the safety of the SSRIs in the treatment of MDD. Whereas in adults the well-documented efficacy of SSRIs ensures a favorable risk/benefit balance, the paucity of information in the pediatric population has made it difficult for clinicians and regulators to reach the same conclusion in youths. The

\footnotetext{
1University of Nebraska Medical Center, Omaha, Nebraska.

${ }^{2}$ National Institute of Mental Health, Bethesda, Maryland.

3Johns Hopkins University, Baltimore, Maryland.

4University of Texas Southwestern, Dallas, Texas.

${ }^{5}$ Baystate Medical Center, Springfield, Massachusetts.

6University of Pennsylvania School of Medicine and Children's Hospital of Philadelphia, Philadelphia, Pennsylvania.

${ }^{7}$ Duke University Medical Center, Durham, North Carolina.
} 
recent availability of meta-analyses completed by regulatory agencies of published and unpublished industry-sponsored trials, epidemiological studies of youth suicide and medication use, and the Treatment for Adolescents with Depression Study (TADS) (TADS Team 2004) have expanded our knowledge-base regarding the efficacy and safety of SSRIs in young patients. Based on currently available data, we provide in this paper a critical discussion of potential risks and benefits of SSRIs in the treatment of children and adolescents with depression.

\section{Background and context}

Fluoxetine, the first SSRI approved in the United States for the treatment of MDD, was made commercially available in 1987. As early as 1991, the U.S. Food and Drug Administration (FDA) held a public meeting to address concerns that fluoxetine was potentially contributing to suicidal behaviors in adults. An analysis of data pooled from 17 double-blind clinical trials was presented by fluoxetine's manufacturer, Eli Lilly \& Co. (Indianapolis, IN). This analysis showed a greater decline in symptoms of suicidality endorsed on the Hamilton Depression Scale by adult patients taking fluoxetine than those taking placebo (Beasley et al. 1991). Subsequently, reviews of clinical trials submitted to the FDA involving nine antidepressants and 48,000 subjects (77 of whom completed suicide) did not find a statistically significant difference in the risk for suicide or suicide attempt between SSRIs and placebo, or between SSRIs and other types of antidepressants (Khan et al. 2003; Khan et al. 2000).

The early pediatric literature on the treatment of MDD with SSRIs was primarily limited to case reports and small, open-label trials. It wasn't until 1997 that the first randomized, double-blind, placebo-controlled trial showing the efficacy of fluoxetine in children and adolescents (age, 7-18 years) with MDD was published (Emslie et al. 1997). In this National Institute of Mental Health (NIMH)-funded study, $56 \%$ of the subjects in the fluoxetine group had improved at the end of the 8-week trial compared with $33 \%$ in the placebo group $(p<0.05)$. In 1998, based, in part, on that trial, the practice guidelines published by the Amer- ican Academy of Child and Adolescent Psychiatry (AACAP) recommended SSRIs as initial therapy in the acute phase of MDD (Birmaher et al. 1998). This was followed by an increase in prescribing SSRIs for youths. The number of adolescents who received an antidepressant at the index visit of a new episode of depression grew from 5\% at that point in 1998 to $37 \%$ in 2002 (Valuck et al. 2004).

With the advent of the FDA Modernization Act (U.S. Congress 1997), which provided 6 months of additional market exclusivity for pediatric studies, the number of industrysponsored MDD studies in children and adolescents grew (Emslie et al. 2002; Wagner et al. 2003; Wagner et al. 2004). Publications of industryconducted, double-blind, placebo-controlled trials of fluoxetine, paroxetine, sertraline, and citalopram reflected this expanding level of activity. Following two positive randomized clinical trials involving 315 youths 8-18 years of age (Emslie et al. 2002; Emslie et al. 1997), the FDA approved fluoxetine for the treatment of pediatric MDD in January 2003. Fluoxetine remains the only drug that is FDA-approved for the treatment of depression in children and adolescents. In fact, most of the pediatric trials in depression have failed to discriminate between active medication and placebo on primary efficacy measure. Whereas this situation is not substantially different from that in adult depression, given the notoriously high rate of response on placebo, it must be pointed out that a particular feature of the FDA pediatric exclusivity rule may contribute to it. In fact, the 6month additional exclusivity is granted for merely conducting a pediatric trial and not necessarily for showing efficacy.

Then, in mid-2003, the Medicine and Health Care Products Regulatory Agency (MHRA) of the British Department of Health issued a report concluding that paroxetine was contraindicated in patients with MDD under the age of 18 . This decision was based on an examination of proprietary data, including both published and unpublished data, that demonstrated a slight increase in suicidal ideation and behavior (suicidality) among patients randomized to paroxetine as compared with those who received placebo (3.7\% versus $2.5 \%)$ and a lack of statistically significant benefit. 
The MHRA notice proved to be the first in a series of notices by both the FDA and MHRA expressing concerns regarding antidepressants in the treatment of pediatric depression. It also marked the beginning of extensive analyses conducted by both regulatory agencies and two public hearings in 2004 regarding SSRIs and suicidality, this time with a focus on the pediatric population.

In December 2003, the MHRA completed a summary analysis of their data regarding antidepressant use in pediatric depression. They reported that there was no evidence of efficacy for any SSRI in pediatric depression, except for fluoxetine. Additionally, the MHRA described a rate of adverse events that exceeded those of placebo in many trials, with specific concerns regarding suicidality. The MHRA concluded that even if the risks were minimal, if there is no evidence of benefit for the other antidepressants, then the risk/benefit relationship for these medications would be unacceptable.

In February 2004, the FDA convened a joint meeting of their Psychopharmacologic Advisory Committee and Pediatric Subcommittee of the Anti-Infective Drugs Advisory Committee in order to evaluate the use of antidepressants in children and adolescents. The goal of this meeting was to review the safety and efficacy data available through controlled trials of antidepressants in children and adolescents. The FDA was particularly concerned with examining the adverse events data regarding the emergence or occurrence of suicide-related events, including suicidal thinking as well as actual self-harm. In the course of this review, it became apparent that there were marked differences in methods of data collection, coding, and analyses of adverse event data across studies. This necessitated a review and reclassification of the suicidality adverse events in order to accurately assess the available data. In March 2004, as these analyses were being conducted, the FDA issued a public health advisory, as an interim step, asking manufacturers of 10 different antidepressant drugs to include in their label a warning section recommending close scrutiny for worsening depression or emergence of suicidality in adult and pediatric patients treated with these agents (FDA 2004a).
In September 2004, the results of a metaanalysis of 24 controlled clinical trials of nine antidepressants in approximately 4400 pediatric patients were presented at a public hearing. The 24 trials were conducted for various indications, primarily MDD, but also for anxiety and attention-deficit/hyperactivity disorder (ADHD). Although no completed suicides occurred in these trials, the cumulative risk for suicidality when adverse events were collected by spontaneous report was approximately $4 \%$ on active medication versus approximately $2 \%$ on placebo, resulting in a relative risk of approximately 2 and a risk difference of $2 \%$ (Hammad 2004). When data was systematically collected utilizing rating scales at baseline and routinely throughout the trials, the overall rates of treatment-emergent suicidality and suicidal worsening were higher than was reported using spontaneous adverse event reports, but there was no difference between the rates in the placebo and active drug groups (Hammad 2004).

Based on the recommendations of the committee, the FDA took the following four actions (FDA 2004b). They issued a "black box" warning that antidepressant use in children was accompanied by an increased risk for suicidality. The warning was not limited to SSRIs, but involved all antidepressants, and was not specific for depression, but included any use in pediatric populations. Secondly, they required a medication guide to accompany all prescriptions. The medication guide included information for parents regarding monitoring for suicidality and adverse events with antidepressants. Thirdly, they established guidelines for frequency of monitoring when initiating antidepressants. Face-to-face follow-up with the clinician weekly for 4 weeks, then every other week for 4 weeks, and then monthly. And finally, they initiated unit-of-use packaging to ensure that every patient receives the medication guide each time a prescription is filled.

The findings regarding suicidality have forced clinicians to carefully consider the existing data on: (1) The efficacy of antidepressants in this population, (2) the potential harm of these medications, and (3) what the implications are for the treatment of children and adolescents in their own practice. 


\section{Efficacy data}

In 2004, the FDA reviewed both published and unpublished data on the efficacy of SSRIs in pediatric depression and concluded that only 3 (two fluoxetine and one citalopram) of 15 pediatric MDD trials showed evidence of efficacy, defined as a statistically significant $(p<0.05)$ superiority of active medication over placebo on the primary outcome measure (Table 1). (Note: The results of TADS were not yet available at the time this summary was prepared.) Three other trials (Keller et al. 2001; Wagner et al. 2003) were believed to provide some suggestion of potential benefit, but they did not meet FDA guidelines for a "positive" efficacy study. The trial of paroxetine (Keller et al. 2001) was positive on several secondary endpoints, though not on the primary outcome, while the two trials of sertraline showed a positive pri- mary endpoint only when their data were pooled and analyzed (Wagner et al. 2003).

These data provide support for the FDA indication of fluoxetine for pediatric depression. The summary of these data also highlight the fact that the majority of studies conducted to date on pediatric depression were unpublished and that all of the unpublished studies were negative studies (i.e., did not demonstrate a benefit of active medication compared to placebo on the primary outcome measure).

Published versus unpublished data. Clinicians and the general public receive their information on clinical trials through published data. A meta-analysis assessed conclusions based on published data and contrasted those to conclusions reached by combining published and unpublished data (Whittington et al. 2004).

Table 1. Primary Outcome Results for Acute (8-12 Week) Placebo-Controlled Pediatric Studies of SSRIs ANd Related SERotonergic Drugs in Major Depression

\begin{tabular}{llcccc}
\hline & \multicolumn{1}{c}{ Publication } & N & $\begin{array}{c}\text { Primary outcome } \\
\text { continuous } \\
\text { measure }\end{array}$ & $\begin{array}{c}\text { Age } \\
\text { range } \\
\text { (years) }\end{array}$ & $\begin{array}{c}\text { Outcome* } \\
\text { versus placebo) }\end{array}$ \\
\hline Paroxetine & Keller et al. 2001 & 275 & HAM-D & $12-18$ & Negative $^{\text {a }}$ \\
Paroxetine & Berard et al. 2006 & 275 d & MADRS & $13-18$ & Negative \\
Paroxetine & Emslie et al. in press & 203 e & CDRS-R & $7-17$ & Negative \\
Fluoxetine & Emslie et al. 2002 & 219 & CDRS-R & $8-18$ & Positive \\
Fluoxetine & Emslie et al. 1997 & 96 & CDRS-R & $8-17$ & Positive \\
Fluoxetine & TADS 2004 & 439 & CDRS-R & $12-17$ & Positive \\
Sertraline & Wagner et al. 2003 & 160 & CDRS-R & $6-17$ & Trend \\
Sertraline & Wagner et al. 2003 & 160 & CDRS-R & $6-17$ & Negative \\
Venlafaxine & Unpublished & 161 & CDRS-R & $7-17$ & Negative \\
Venlafaxine & Unpublished & 193 & CDRS-R & $7-17$ & Negative \\
Citalopram & Wagner et al. 2004 & 174 & CDRS-R & $7-17$ & Positive \\
Citalopram & Unpublished & 244 & CDRS-R & $13-18$ & Negative \\
Nefazodone & Unpublished & 195 & CDRS-R & $12-18$ & Trend \\
Nefazodone & Unpublished & 273 & CDRS-R & $7-17$ & Negative \\
Mirtazapine & Unpublished & 126 & CDRS-R & $7-17$ & Negative \\
Mirtazapine & Unpublished & 124 & CDRS-R & $7-17$ & Negative \\
\hline
\end{tabular}

Source: Adapted from Laughren TP. Memorandum, January 5, 2004: Background comments for February 2, 2004 Meeting of Psychopharmacological Drugs Advisory Committee (PDAC) and Pediatric Subcommittee of the AntiInfective Drugs Advisory Committee (AC), Bethesda, MD.

*Positive $(p \leq 0.05)$; negative $(p \geq 0.10)$; Trend $(0.05<p \leq 0.10)$ on primary efficacy outcome.

aKeller et al. 2001; positive on most secondary endpoints.

bWagner et al. 2003; positive on pooling of two studies.

cMany studies also included responder rate as a primary categorical outcome in addition to the continuous rating of depressive symptoms.

SSRIs = selective serotonin reuptake inhibitors; HAM-D = Hamilton Depression Rating Scale; MADRS=

Montgomery-Åsberg Depression Rating Scale; CDRS-R = Childhood Depression Rating Scale-Revised.

d286 randomized, but only 275 analyzed.

e206 randomized, but only 203 analyzed. 
Five published, acute, randomized, placebocontrolled trials of SSRIs in pediatric depression were compared with all unpublished data included in the United Kingdom's Committee on Safety of Medicines' review. All of the fluoxetine trials had been published, and two trials (Emslie et al. 2002; Emslie et al. 1997) supported its efficacy in pediatric major depression, suggesting a favorable risk/benefit profile. The published results of one paroxetine trial and two sertraline trials suggested equivocal or weakly positive efficacy which, in the case of paroxetine, was not supported by two other then-unpublished trials (Berard et al. 2006). Likewise, efficacy of citalopram was supported by one published trial (Wagner et al. 2004) but not by an unpublished one (Table 1). For venlafaxine and mirtazapine, two unpublished trials for each compound did not demonstrate efficacy. In the face of unproven efficacy and the potential for suicidality as an adverse event, the authors concluded that the risk/benefit profiles for paroxetine, sertraline, venlafaxine, and mirtazipine were unfavorable (Whittington et al. 2004; Whittington et al. 2005).

The discrepancies between published and unpublished data highlight the potential for biased reporting of positive versus negative results. Whittington et al. (2005) expressed concerns that clinical guideline development and clinical decisions regarding treatment are largely dependent on the evidence base established through peer-reviewed journals and that nonpublication of trials could lead to erroneous recommendations for treatment.

TADS data. The Treatment for Adolescents with Depression Study (TADS) is an NIMHsponsored multisite trial comparing fluoxetine, cognitive behavioral therapy (CBT), their combination, and placebo in 439 adolescents with a primary diagnosis of major depression (TADS Team 2004). The acute-phase TADS results were not available at the time of the initial FDA advisory committee meeting in February 2004, but they were published and available by the time the committee reconvened in September of that year. TADS is significant in that it was the largest acute treatment study of depression in youths. Additionally, TADS had a psychosocial treatment arm, both stand alone and in combination with fluoxetine, which had not been included in previous antidepressant trials.

TADS had two primary outcome measures, the scalar Children's Depression Rating ScaleRevised (CDRS-R; Poznanski and Hartmut 1996) total score and the end-of-treatment response rate defined by a categorical Clinical Global Impression-Improvement score (CGI-I) of much or very much improved. CDRS-R adjusted mean (standard deviation) scores at baseline, week 6, and week 12 were: CBT with fluoxetine 60.79 (4.85), 38.10 (7.78), 33.79 (8.24); fluoxetine alone $58.94(4.00), 39.80$ (7.37), 36.30 (8.18); CBT alone 59.64 (4.52), 44.63 (8.30), 42.06 (9.18); placebo 61.18 (4.27), 44.90 (7.32), 41.77 (7.99). Pairwise contrasts on the CDRS-R regression slope coefficients showed that combination treatment with fluoxetine and CBT was statistically superior to placebo $(p=0.001)$, CBT $(p=0.001)$, and fluoxetine $(p=0.02)$, whereas fluoxetine alone was statistically superior to CBT $(p=0.01)$ but not placebo $(p=0.10)$. Supporting analyses performed on the week 12 CDRS-R adjusted means demonstrated fluoxetine with CBT $(p=0.001)$ and fluoxetine alone $(p=0.002)$ to be superior to placebo, whereas CBT alone was not $(p=0.97)$. Fluoxetine with CBT was superior to CBT alone ( $p=$ $0.001)$ but not to fluoxetine alone $(p=0.13)$, whereas fluoxetine alone was superior to CBT alone $(p=0.001)$. The other primary efficacy outcome measure, the CGI-I-defined rates of response, showed that more patients were responders to combination therapy $(71 \%)$ or fluoxetine $(61 \%)$ than to CBT $(43 \%)$ or placebo (35\%; $p \leq 0.01$ ) (TADS Team 2004).

Thus, on one of the two primary analyses, fluoxetine approached statistical significance compared to placebo, although it was significantly better than CBT. However, the preponderance of the evidence from the other positive primary analysis and supporting analyses, using end-of-treatment CDRS-R scores, supports, the use of fluoxetine alone in decreasing depressive symptoms.

The clinical impact of treatment on outcome was evaluated by calculating the effect size and the number needed to treat (NNT) to each additional responder, based on the adjusted means. The effect size derived from the CDRS$\mathrm{R}$ was 0.98 for fluoxetine with CBT, 0.68 for 
fluoxetine alone, and -0.03 for CBT alone. Effect sizes from the odds ratio (OR) for the dichotomized CGI-I were 0.84 for fluoxetine with CBT, 0.58 for fluoxetine alone, and 0.20 for CBT alone. The NNT for the dichotomized CGI-I for fluoxetine and CBT was 3 (95\% Confidence Interval [CI], 2-4), for fluoxetine alone was 4 (95\% CI, 3-8), and for CBT alone 12 (95\% CI, 5-23). Thus, the largest study to date of adolescent depression provided clear evidence of fluoxetine's efficacy in adolescents with moderate to severe depression.

Summary. Based upon these clinical trials, fluoxetine does appear to have efficacy in the treatment of pediatric depression, with the majority of the trials demonstrating positive results. These data, combined with the TADS data suggesting that psychotherapy alone faired poorly compared to fluoxetine and that the best treatment combination has fluoxetine as a component, would lend support to the use of fluoxetine in the treatment of pediatric MDD. Support for efficacy also exists for sertraline, citalopram, and paroxetine. However, the efficacy signal for these drugs is weaker and inconsistent, as shown by the inability to replicate it in other studies. It is entirely possible that this variability in outcome is similar to what is seen in the adult literature, where antidepressants approved by the FDA for the treatment of adult MDD frequently have as many negative as positive trials. Finally, no efficacy signal has emerged for venlafaxine or mirtazapine. Whether the discrepancy between the fluoxetine and other SSRI's data is better explained by ex- perimental error owing to methodological factors in study design and conduct (more likely, as evidenced by the variability in placebo response) or by substantive pharmacological differences (less likely) remains a matter of debate.

\section{Safety data}

Risk of treatment. In September 2004, when the FDA presented results of their meta-analysis of 25 trials plus TADS, safety data were presented in addition to the efficacy data (Hammad 2004). In order to make the clinical trial datasets more uniform with respect to adverse event reporting, an independent team of experts utilized a novel approach developed by researchers at Columbia University to evaluate and recode all adverse events for suicidal and self-injurious behaviors (suicide attempt, preparatory acts, suicidal ideation, and so forth). Following reclassification, 78 of the approximately 4400 subjects from these datasets $(1.7 \%)$ were coded as experiencing either suicidal behavior $(n=33)$ or suicidal ideation $(n=$ 45). Once a uniform classification was applied, relative risks for suicidal ideation and behavior were calculated by drug and by study indication (Table 2). There were no completed suicides, and only venlafaxine and fluoxetine in TADS exhibited a statistically significant signal for suicidality (suicide attempts or suicidal ideation). The overall relative risk (RR) for suicidality was 1.66 (95\% CI; 1.02, 2.68) for MDD trials and $1.95(1.28,2.98)$ for all trials, all indications. The authors of the analysis concluded that: "Although the difference is small, it seems

Table 2. Overall Relative Risks of Suicidal Behavior or Ideation by Drugs in MDD Trials as Defined by the Columbia University Reclassification Project (Hammad 2004)

\begin{tabular}{lcc}
\hline Drug & Relative risk $(95 \%$ CI $)$, MDD trials & Relative risk $(95 \%$ CI $)$, all trials, all indications \\
\hline Citalopram & $1.37(0.53,3.50)$ & $1.37(0.53,3.50)$ \\
Fluvoxamine & No MDD trials & $5.52(0.27,112.55)$ \\
Paroxetine & $2.15(0.71,6.52)$ & $2.65(1.00,7.02)$ \\
Fluoxetine (including TADS) & $1.53(0.74,3.16)$ & $1.52(0.75,3.09)$ \\
Sertraline & $2.16(0.48,9.62)$ & $1.48(0.42,5.24)$ \\
Venlafaxine & $8.84(1.12,69.51)$ & $4.97(1.09,22.72)$ \\
Mirtazapine & $1.58(0.06,38.37)$ & $1.58(0.06,38.37)$ \\
Nefazodone & No events & No events \\
Bupropion & No MDD trials & No events \\
\hline
\end{tabular}

MDD = major depressive disorder; $\mathrm{CI}=$ Confidence Interval. 
likely that the effect is real, because the findings were statistically significant in aggregate and are consistent across multiple studies of various agents" (Brent 2004).

This issue can be analyzed in terms of "risk difference," which provides an estimate of the absolute increase in risk of the event of interest attributable to treatment, in this case, suicidality. This is calculated by subtracting the risk in the placebo group from the risk in the active drug group. The overall risk difference for the SSRIs in the MDD trials is approximately $2 \%$. In other words, 2 patients of 100 treated with an SSRI for major depression would be expected to have an increase in suicidality during shortterm treatment attributable to the drug. Suicidality, when it did occur, was primarily ideation, with only a minority of events involving actual suicide attempts (27 suicide attempts, 6 "preparatory actions)," and 45 suicidal ideation events). Additional risk beyond that is inherent in the disorder being treated (Hammad 2004).

In addition to an increase in the risk of suicidality, SSRIs are almost twice as likely as placebo to cause increased agitation and hostility during acute treatment (Table 3). At this time, it is unclear whether the increased risk for suicidality associated with these medications is mediated by the agitation and hostility symptoms, but it is important for patients and families to be aware of this potential.

FDA conclusions regarding risk. The advisory committee to the FDA concluded that the ad-

Table 3. Overall Relative Risk of TreatmentEmergent Agitation or Hostility by Drug IN MDD TRIALS (HAMMAD 2004)

\begin{tabular}{ll}
\hline Drug & Relative risk $(95 \% \mathrm{CI}), \mathrm{MDD}$ trials \\
\hline Citalopram & $1.87(0.34,10.13)$ \\
Paroxetine & $7.69(1.80,32.99)$ \\
Fluoxetine (does not include & $1.01(0.40,2.55)$ \\
$\quad$ & \\
TADS) & $2.92(0.31,27.83)$ \\
Sertraline & $2.86(0.78,10.44)$ \\
Venlafaxine extended-release & $0.52(0.03,8.27)$ \\
Mirtazapine & $1.09(0.53,2.25)$ \\
Nefazodone & $1.79(1.16,2.76)$ \\
All drugs &
\end{tabular}

$\mathrm{MDD}=$ major depressive disorder $\mathrm{CI}=$ Confidence Interval. verse events reported voluntarily during clinical trials in aggregate did indicate an increased risk of treatment-emergent suicidality. Although there was variability in the adverse event data, the committee was unable to conclude that any single antidepressant was free of risk. The committee suggested additional research is needed to further delineate the risks and benefits of these drugs in pediatric patients with psychiatric illness. Additional efficacy data and more safety data focusing specifically on suicidality are needed. Long-term trials using placebo and fluoxetine as controls, as well as additional NIH projects aimed at improving our understanding of the natural and longitudinal course of depression and suicidality, would better inform clinicians how to diagnose and treat pediatric depression. The risks associated with pharmacological and nonpharmacological interventions, as well as the risks of not treating depressed children and adolescents, should also be assessed (FDA 2004b).

Since the FDA's October 2004 "black box" warning and additional recommendations regarding antidepressant use in children, other regulatory bodies have also released warnings. In April 2005, the European Medicines Agency issued a press release regarding their review of SSRI and SNRI medicines in children and adolescents (atomoxetine, citalopram, duloxetine, escitalopram, fluoxetine, fluvoxamine, mianserine, milnacipran, mirtazapine, paroxetine, reboxetine, sertraline and venlafaxine). They recommended: "... strong warnings across the whole of the European Union to doctors and parents about these risks. Doctors and parents will also be advised that these products should not be used in children and adolescents except for their approved indications." Approved indications in the pediatric population are limited to obsessive-compulsive disorder (OCD) for a few of the agents and ADHD for atomoxetine (European Medicines Agency 2005).

TADS data pertaining to risk. TADS provided a systematic approach to collecting data on suicidality, beginning at baseline and continuing to all subsequent endpoints, which allows for a longer-term assessment of the role of various treatments on suicide. At baseline, clinically 
significant suicidal thinking was present in 29\% of the sample, as measured by the CDRS-R suicide item and the Suicidal Ideation Questionnaire-Junior High School Version (SIQ-Jr; Reynolds 1987). Suicidality declined significantly in all four treatment groups with fluoxetine plus CBT showing the greatest reduction $(p=0.02)$. There were no completed suicides in the course of the study, but $24(5.5 \%)$ of the 439 TADS patients experienced a suicide-related event. Seven (7) of the 24 suicide-related events were suicide attempts $(1.6 \%$ of the total sample). Four (4) of the attempts were by patients assigned to fluoxetine and CBT, 2 to fluoxetine alone, and 1 to CBT alone. None of the subjects taking placebo attempted suicide.

Harm-related events, which included thoughts or behaviors related to harm of self as well as harm to others, occurred in $11.9 \%$ of those assigned to fluoxetine alone, $8.4 \%$ fluoxetine with CBT, $4.5 \%$ CBT alone, and $5.4 \%$ placebo.

Overall, suicidality decreased with treatment. Improvement was greatest for those receiving combination treatment and least for those receiving fluoxetine alone. It is important to note that, though fluoxetine did not appear to increase suicidal ideation, the harm-related adverse events did occur more frequently in fluoxetine-treated patients (TADS Team 2004).

Epidemiological and observational data. Although no causality can be determined, nonexperimental studies using community or observational data offer a perspective complementary to the information from controlled clinical trials of antidepressant use in children and adolescents.

Whereas the pediatric use of antidepressants has substantially increased throughout the previous decade, the overall youth suicide rates had been declining (Olfson et al. 2003). During 1992-2001, for example, the overall suicide rate among persons 10-19 years of age declined from 6.2 to 4.6 per 100,000 population (CDC 2004). A significant inverse relationship was also found between regional rates of antidepressant medication use and suicide rates of 10- to 19-year-old youths in the United States in 1990-2000. Each 1\% increase in antidepressant use was associated with a decrease of 0.23 suicides per 100,000 adolescents per year.
Valuck et al. assessed antidepressant use in youth by analyzing a large database of insurance claims from both commercial and Medicaid plans. They examined claims filed (January 1997 to March 2003) from various regions across the United States on adolescents newly diagnosed with MDD who had at least 6 months of follow-up data (Valuck et al. 2004). The database of 24,119 adolescents revealed crude suicide attempt rates, ranging from $0.0 \%$ to $2.3 \%$. Treatment with SSRIs (hazard ratio $[\mathrm{HR}]=1.59$; $\mathrm{CI}, 0.70,2.89)$, other antidepressants (HR = $1.03 ; \mathrm{CI}, 0.43,2.44)$, or multiple antidepressants $(\mathrm{HR}=1.43 ; \mathrm{CI}, 0.70,2.89)$ after index MDD diagnosis resulted in no statistically significant increase in risk of suicide attempt. Thus, whereas the SSRIs were associated with a numerically higher risk of suicide attempt (HR 1.59), the increase failed to reach statistical significance. Treatment with an antidepressant medication for at least 180 days reduced the likelihood of a suicide attempt, as compared to treatment courses of less than 55 days $(\mathrm{HR}=0.34 ; \mathrm{CI}$, $0.21,0.55)$. The authors concluded that antidepressants had no statistically significant effects on the likelihood of suicide attempts.

A review of National Vital Statistics from the Centers for Disease Control and Prevention analyzed records of all U.S. individuals at the county level who committed suicide between 1996 and 1998, examining the association between antidepressant prescription and suicide rate (Gibbons et al. 2005). Change in prescription rates of tricyclic antidepressants (TCAs), SSRIs, and other non-SSRI antidepressants from 1996 to 1998 were obtained for each county. The data demonstrated lower suicide rates in association with increased use of selective serotonin reuptake inhibitors and new-generation non-SSRIs, compared to TCA use. Suicide rates tended to be higher in counties with larger proportions of TCA prescriptions. As the authors point out, this type of data cannot demonstrate causal relationships because the higher number of TCA prescriptions may simply be a marker for counties with more limited access to mental health care. The higher rates of suicides with TCA prescriptions may also reflect the greater toxicity in overdose of TCAs. After adjusting for age, gender, race, income, and county-to-county variability in suicide rates, the overall relationship between all 
prescribed antidepressants and suicide rate was not statistically significant $(p=0.14)$.

Jick et al. conducted an evaluation of antidepressant prescriptions utilizing a matched casecontrol design based on patients' prescriptions / diagnoses in the U.K. General Practice Research Database (GPRD), 1993-1999 (Jick et al. 2004). Data were collected on patients 10-69 years of age treated with amitriptyline, fluoxetine, paroxetine, and dothiepin (reference group), assessing cases of nonfatal suicide behavior (ideation or attempts) $(n=555)$, suicides $(n=17)$, and controls $(n=2062)$ without suicidal behavior. Compared to dothiepin, there was no statistically significant difference in suicidality with one antidepressant compared to another, with a range for the relative risk (RR) for nonfatal suicide behavior of $0.83-1.29$. Results were similar for patients 10-19 years of age, although the sample of adolescent cases was small. There were no suicides in the 10-19 year olds prescribed medication in this study population. However, in reviewing the entire GPRD population from 1993 to 1999, 15 persons in this age group had committed suicide, none of whom had received an antidepressant drug.

Jick et al.'s evaluation of the time-course of suicidal events is also of clinical interest. The RR of nonfatal suicidal behavior/suicide was highest for patients within 1-9 days of the antidepressant being prescribed (versus 90 days or more). The RR for nonfatal suicidal behavior during this earlier time period was 4.07 (95\% CI, 2.89-5.74), whereas the RR for suicide was 38.0 (95\% CI, 6.2-231). Although this could indicate an exacerbation of suicidality during the initiation of treatment, it could also be related to the acuity that prompted the initiation of the treatment. It has been reported, even prior to the antidepressant era, that people were most likely to commit suicide as they were coming out of a depressive episode.

Also, though it has been hypothesized that abrupt discontinuation of antidepressants may play a role in exacerbation of symptoms and suicidality, there was no statistically significant association between discontinuation of an antidepressant and nonfatal suicidal behavior.

Another way to determine whether SSRIs are implicated in completed suicides is through toxicological analysis of individuals dying from suicide. A study of suicide in more than 5000 adults found that, most often, antidepressants had not been taken immediately before death, even though the majority of the persons had been depressed (Isacsson et al. 1997). A study of 14,857 suicides and 26,422 other deaths in Sweden (Isacsson et al. 2005) found that none of the 15 suicides below the age of 15 years had an SSRI detected on toxicology. In 15-19-yearold suicide victims, SSRIs had a lower relative risk in suicides compared with non-SSRIs. These findings do not support the suggestion that SSRIs are triggering suicides in adults or youth.

In a study of 49 adolescent suicides in Utah, $24 \%$ had been prescribed antidepressants, but none had tested positive for SSRIs at the time of death (Gray et al. 2003). In a postmortem study conducted on 66 suicides among persons under 18 years of age in New York City from 1993 through 1998 (Leon et al. 2004), 54 $(81.8 \%)$ had serum toxicological analysis for antidepressants and an injury-death interval of 3 days or less. Imipramine was detected in 2 victims and fluoxetine in another 2 (total 10\%). None of the other $90 \%$ of suicides had antidepressants detected. Most postmortem studies in adults have found that over $80 \%$ of depressed patients at the time of suicide are not on antidepressants.

Risk of nontreatment. When weighing the potential risks and benefits of treatment, it is also important to consider the risk of not treating MDD. Suicide is the third-leading cause of death among adolescents 15-19 years of age, and fourth-leading cause of death among 10to 14 year olds (Anderson 2002). The depressed pediatric subjects followed by Fombonne et al. into adulthood demonstrated a suicide risk of $2.45 \%$, with $44.3 \%$ of the sample attempting suicide once in their lives (Fombonne et al. 2001).

Weissman et al. also found an elevated risk of suicide and comorbidity in long-term follow-up studies of depression. During a period spanning approximately 10 years between adolescence and early adulthood, they estimated a 5 -fold increased likelihood of suicide attempt associated with pediatric depression (Weissman et al. 1999a; Weissman et al. 1999b). Prepubertal children with an earlier age of MDD onset are also at increased risk for substance abuse, 
conduct disorder, overall impaired functioning, and need for long-term psychiatric and medical services (Weissman et al. 1999b). Clinical outcomes in adulthood of adolescent onset MDD demonstrated a high rate of suicide (7.7\%) and a 5-fold increase for a first suicide attempt (Weissman et al. 1999a).

Unfortunately, the available treatment interventions have limited data on acute efficacy and unproven effectiveness in improving the long-term outcome of the disorder. Nonetheless, fluoxetine remains the most effective acute intervention, either alone or in combination with psychotherapy, for decreasing depressive symptoms in adolescents suffering from moderate to severe depression. However, specialized psychotherapy alone does not seem to be a valid therapeutic option for these moderately to severely depressed patients (TADS Team 2004).

Summary. Analyses of suicidality adverse events collected in the pediatric antidepressant trials have demonstrated an elevation in suicidality when placebo was compared to active medication. Systematic and repeated assessments of suicidality using symptom rating scales, however, have not supported this finding. In fact, when these data were collected in TADS at baseline, 6 weeks, and 12 weeks, all four treatment groups demonstrated a decline in suicidality, with the greatest decline occurring in the group receiving fluoxetine with CBT. Also of interest are the epidemiological and observational data, which demonstrate an increase in the use of SSRIs in the pediatric population but no corresponding increase in completed suicides. In fact, studies have generally identified an inverse correlation, both nationally and regionally, with suicide and antidepressant usage.

\section{DISCUSSION}

The pharmacological treatment of pediatric depression has recently undergone intensive scrutiny and discussion. Throughout the process, a better understanding of the potential risks and benefits has evolved. There is a clear need for additional clinical trials to systematically assess these issues, but this will obviously be an extended process. At this point, the task for the clinician is to be aware of what information is available and to make an informed decision regarding the balance between potential benefits and risks when deciding upon a treatment plan for the individual patient.

Various statistical methods can be employed to assess benefit versus risk (Whittington et al. 2004). However, interpretation of these data must ultimately be conducted in a clinical context. The decision as to whether the calculated risk is favorable, for example, to induce one adverse event for every 10 patients showing improvement, is dependent on the severity of the event and the presence of better alternatives.

It is possible that, at times, the ease of use, tolerability, and perceived efficacy of the SSRIs in clinical practice led to an overly casual pattern of usage in treating pediatric disorders. Despite increasing rates of antidepressant usage, it is difficult to argue that these medications are overprescribed, as the ratio of prescriptions for the treatment of depression to prevalence of MDD remains much less than one.

Considerable evidence supports the use of fluoxetine for pediatric MDD. However, even fluoxetine carries risks, which must be considered in the risk/benefit analysis and treatment planning. The TADS Team concluded that: "The combination of fluoxetine with CBT offered the most favorable tradeoff between benefit and risk for adolescents with major depressive disorder" (TADS Team 2004). Combination therapy may be the best treatment for teenagers with major depression, especially when the depression is moderate to severe and there is a history of past or present suicidality. Whereas CBT alone was not better than placebo, and, by most measures, was inferior to combination treatment or fluoxetine alone, it proved to be a useful adjunct to pharmacotherapy. CBT also demonstrated usefulness, both alone and in combination with fluoxetine, in the reduction of suicidal thoughts and behaviors. Because nearly $40 \%$ of depressed teens do not respond to fluoxetine and others aren't able to tolerate it, treatments other than fluoxetine should continue to be studied and be made available. 
What we still do not know

Despite a recent expansion of data, our knowledge base about the efficacy and safety of SSRIs remains limited, with many unanswered questions:

- Are there clinically significant differences between prepubertal and adolescent depression with respect to antidepressant treatment efficacy and safety? If so, what are the underlying causes of such differences?

- Are there clinically significant differences among SSRIs and similarly related antidepressants with respect to efficacy and/or safety?

- What accounts for the apparent discrepancy between the efficacy of SSRIs in adult depression and the much weaker and inconsistent data in the pediatric population? Is pediatric depression a substantively different condition than depression in adults? There is a need to better understand the longitudinal course of child and adolescent depression and its relationship to adult major depression. Are the assessment methods used in pediatric clinical trials not sufficiently sensitive and specific for measuring depression? Because there have been a significant number of adult studies but very few pediatric studies, is the lack of positive pediatric studies simply a manifestation of fewer studies conducted?

- How can one best interpret "negative" trials of antidepressants? It is important to note that negative studies do not necessarily prove a lack of efficacy. The placebo response in depression trials can be significant, owing, in part, to study design and can potentially lead to an inability to demonstrate efficacy, even for a robust treatment. But negative trials cannot be fully dismissed either, especially when they are properly designed and statistically powered to reject the null hypothesis.

- Likewise, are there real differences in safety of SSRIs between children/adolescents and adults? Why is an association between SSRIs and suicidality detectable in pediatric data, but not in the much larger database of adult studies (Martinez et al. 2005)? Will closer examination of adult data reveal that youth are not specifically at risk and the risk regarding suicidality is ubiquitous across developmental stages?

- Which subgroup of depressed youths are the best candidates for antidepressant treatment and which ones are likely to respond to nonpharmacological interventions?

- Randomized clinical trials rely on "suicidality" measures, such as suicidal ideation and suicidal attempts. But what is the relationship between suicidality and completed suicide? Can increased risk for suicidality be considered a valid marker for increased risk for suicide? Epidemiologically, the relationship among suicidal ideation, suicidal attempts, and suicide is not linear, as suicide has decreased in the last 10 years, but rates of suicidal ideation and suicidal attempts have not (Kessler et al. 2005).

- What is the most effective way to monitor patients for safety during treatment with antidepressants? The FDA has issued specific recommendations that the clinician should see children and adolescents on a weekly basis during the 1st month of treatment. This recommendation is based on usual practice in clinical trials, but no empirical evidence currently supports this schedule of visits over less intensive but potentially equally effective approaches (e.g., biweekly visits, with weekly phone contacts between visits).

- We know from controlled studies that there can be an increased risk of self-harm and aggression in the short term, but we do not know if the risk disappears or additional benefits emerge beyond $2-3$ months of treatment.

- How can a clinician distinguish suicidality that is causally related to the treatment delivered from suicidality that emerges as a result of the underlying illness? Stopping antidepressant treatment with the emergence of worsening suicidality may become the norm with the current warnings. However, recent FDA analyses indicate that only $50 \%$ of emerging suicidality 
is related to prescribed treatment and 50\% to other causes, with no way for the clinician to distinguish between the two. This could lead to premature discontinuation of an effective treatment. Additionally, what should a clinician do after a treatment is discontinued for suicidality? Does one make a determination that a child is "allergic" to SSRIs and try nondrug strategies, or challenge with a second SSRI, or prescribe alternatively untested medication or psychotherapy?

The recent concerns about SSRIs have illustrated the value of having conducted 15 randomized clinical trials in pediatric depression in a relatively short period of time. Without data from these trials, no assessment of benefit and risk could have been even attempted. However, studies with small sample sizes, such as those conducted to date, will never answer important safety questions where the outcomes of interest occur infrequently. It is not practical to design a randomized clinical trial with suicide as an endpoint, owing to the sample size and duration of a study necessary to evaluate the risk of such an uncommon event. Moreover, establishing relative risk by drug, drug class, subgrouping (e.g., age, gender, disorder) and understanding some aspect of mechanism (e.g., activation) requires very large samples. Hence, practical clinical trials (March et al. 2004; March et al. 2005) are essential if we are to learn more about predictors and management of risk. It is extraordinary that no one has risen to this challenge, to address this significant public health issue, and advocates for depressed youths shouldn't avoid saying so.

\section{CONCLUSIONS}

Essentially, the present use of SSRIs in the treatment of pediatric depression is an informed consent issue. The clinician must openly discuss the risks and benefits of the various treatment options with the youth and parents prior to the selection of the most appropriate treatment for that specific child. With the increase in clinical trials and epidemiological databases, clinicians can more accurately discuss the risk/benefit relationships. However, much remains to be discovered and learned about the treatment of pediatric depression.

\section{DISCLOSURES}

Dr. Kratochvil receives grant support from Eli Lilly and Cephalon, is a consultant to Eli Lilly, Cephalon, Organon, AstraZeneca, and Pfizer, and a member of the Eli Lilly speaker bureau. Dr. Vitiello has no financial ties with pharmaceutical companies. Dr. Walkup receives grant/research support from Eli Lilly, Pfizer, and Abbott, consults to Eli Lilly and JAZZ Pharmaceutical, and has received honoraria from Eli Lilly, Pfizer, and Janssen. Dr. Emslie receives research support from Eli Lilly, Organon Inc., and Forest Laboratories, Inc., is consultant to Eli Lilly, GlaxoSmithKline, Forest Laboratories, Inc., Pfizer, and Wyeth Ayerst, and is on the speaker bureau for McNeil. Dr. Waslick has received research support from Eli Lilly and Johnson and Johnson in the past year, although presently he has no financial ties to any pharmaceutical company. Dr. Weller consults to JAZZ and Pharmac Starr and has research support from Astra Zeneca, Otsuka and Johnson and Johnson. Dr. Burke receives research support from Cyberonics, Forest, Merck, Voyager, Somaxon and Sepracor, and has served on an advisory board and/or received honoraria from Forest and Janssen. Dr. March receives research support from and consults to Eli Lilly and Pfizer and is a consultant to Wyeth and JAZZ.

\section{REFERENCES}

Anderson RN: Deaths: Leading causes for 2000. Natl Vital Stat Rep 50:1-85, 2002.

Beasley CM, Jr, Dornseif BE, Bosomworth JC, Sayler ME, Rampey AH, Jr, Heiligenstein JH, Thompson VL, Murphy DJ, Masica DN: Fluoxetine and suicide: A meta-analysis of controlled trials of treatment for depression. BMJ 303:685-692, 1991.

Berard R, Fong R, Carpenter DJ, Thomason C, Wilkinson C: An International, Multicenter, Placebo-controlled Trial of Paroxetine in Adolescents with Major Depressive Disorder. J Child Adolesc Psychopharmacol 16: 2006. 
Birmaher B, Brent DA, Benson RS: Summary of the practice parameters for the assessment and treatment of children and adolescents with depressive disorders. American Academy of Child and Adolescent Psychiatry. J Am Acad Child Adolesc Psychiatry 37:1234-1238, 1998.

Brent DA: Antidepressants and pediatric depression-the risk of doing nothing. N Engl J Med 351:1598-1601, 2004.

CDC: Methods of suicide among persons aged 10-19 years-United States, 1992-2001. Morb Mortal Wkly Rep 53:471-474, 2004.

Emslie GJ, Heiligenstein JH, Wagner KD, Hoog SL, Ernest DE, Brown E, Nilsson M, Jacobson JG: Fluoxetine for acute treatment of depression in children and adolescents: A placebo-controlled, randomized clinical trial. J Am Acad Child Adolesc Psychiatry 41:1205-1215, 2002.

Emslie GJ, Rush AJ, Weinberg WA, Kowatch RA, Hughes CW, Carmody T, Rintelmann J: A doubleblind, randomized, placebo-controlled trial of fluoxetine in children and adolescents with depression. Arch Gen Psychiatry 54:1031-1037, 1997.

Emslie GJ, Wagner KD, Kutcher S, Krulewicz S, Fong R, Carpenter DJ, Lipschitz A, Machin A, Wilkinson $\mathrm{C}$ : Paroxetine treatment in children and adolescents with major depressive disorder: A randomized, multicenter, double-blind, placebo-controlled trial. J Am Acad Child Adolesc Psychiatry, In press.

European Medicines Agency: European Medicines Agency Press Release, European Medicines Agency finalizes review of antidepressants in children and adolescents. April 25, 2005. Online document at: www.emea.eu.int/pdfs/human/press/pr/ 12891805en.pdf / Accessed on May 13, 2005.

Fombonne E, Wostear G, Cooper V, Harrington R, Rutter M: The Maudsley long-term follow-up of child and adolescent depression. 2. Suicidality, criminality and social dysfunction in adulthood. Br J Psychiatry 179:218-223, 2001.

Gibbons RD, Hur K, Bhaumik DK, Mann JJ: The relationship between antidepressant medication use and rate of suicide. Arch Gen Psychiatry 62:165172, 2005.

Gray D, Moskos M, Keller T: Utah Youth Suicide Study New Findings. Santa Fe, New Mexico, Annual Meeting of the American Association of Suicidology, April 23-26, 2003 (abstract).

Hammad TA: Results of the Analysis of Suicidality in Pediatric Trials of Newer Antidepressants. Psychopharmacology Drugs Advisory Committee and the Pediatric Advisory Committee, September 13-14, 2004. Online document at: www.fda.gov/ohrms/dockets/ac/04/briefing/ 2004-4065b1-10-TAB08-Hammads-review.pdf

Isacsson G, Holmgren P, Ahlner J: Selective serotonin reuptake inhibitor antidepressants and the risk of suicide: A controlled forensic database study of 14,857 suicides. Acta Psychiatr Scand 111:286-290, 2005.
Isacsson G, Holmgren P, Druid H, Bergman U: The utilization of antidepressants-a key issue in the prevention of suicide: An analysis of 5281 suicides in Sweden during the period 1992-1994. Acta Psychiatr Scand 96:94-100, 1997.

Jick H, Kaye JA, Jick SS: Antidepressants and the risk of suicidal behaviors. JAMA 292:338-343, 2004.

Keller MB, Ryan ND, Strober M, Klein RG, Kutcher SP, Birmaher B, Hagino OR, Koplewicz H, Carlson GA, Clarke GN, Emslie GJ, Feinberg D, Geller B, Kusumakar V, Papatheodorou G, Sack WH, Sweeney M, Wagner KD, Weller EB, Winters NC, Oakes R, McCafferty JP: Efficacy of paroxetine in the treatment of adolescent major depression: A randomized, controlled trial. J Am Acad Child Adolesc Psychiatry 40:762-772, 2001.

Kessler RC, Berglund P, Borges G, Nock M, Wang PS: Trends in suicide ideation, plans, gestures, and attempts in the United States, 1990-1992 to 2001-2003. JAMA 293:2487-2495, 2005.

Khan A, Khan S, Kolts R, Brown WA: Suicide rates in clinical trials of SSRIs, other antidepressants, and placebo: Analysis of FDA reports. Am J Psychiatry 160:790-792, 2003.

Khan A, Warner HA, Brown WA: Symptom reduction and suicide risk in patients treated with placebo in antidepressant clinical trials: An analysis of the Food and Drug Administration database. Arch Gen Psychiatry 57:311-317, 2000.

Leon AC, Marzuk PM, Tardiff K, Teres JJ: Paroxetine, other antidepressants, and youth suicide in New York City: 1993 through 1998. J Clin Psychiatry 65:915-918, 2004.

March JS, Silva SG, Compton S, Anthony G, DeVeaugh-Geiss J, Califf R, Krishnan R: The Child and Adolescent Psychiatry Trials Network (CAPTN). J Am Acad Child Adolesc Psychiatry 43:515-518, 2004.

March JS, Silva SG, Compton S, Shapiro M, Califf R, Krishnan R: The case for practical clinical trials in psychiatry. Am J Psychiatry 162:836-846, 2005.

Martinez C, Rietbrock S, Wise L, Ashby D, Chick J, Moseley J, Evans S, Gunnell D: Antidepressant treatment and the risk of fatal and nonfatal selfharm in first-episode depression: Nested casecontrol study. BMJ 330:389, 2005.

Olfson M, Shaffer D, Marcus SC, Greenberg T: Relationship between antidepressant medication treatment and suicide in adolescents. Arch Gen Psychiatry 60:978-982, 2003.

Poznanski EO, Hartmut BM: Children's Depression Rating Scale-Revised (CDRS-R). Los Angeles, Western Psychological Services, 1996.

Reynolds WM: Professional Manual for the Suicidal Ideation Questionnaire. Odessa Florida, Psychological Assessment Resources Inc., 1987.

TADS Team: Fluoxetine, cognitive-behavioral therapy, and their combination for adolescents with depression: Treatment for Adolescents With De- 
pression Study (TADS) randomized, controlled trial. JAMA 292:807-820, 2004.

U.S. Food and Drug Administration: Summary minutes of the CDER Psychopharmacological Drugs Advisory Committee and the FDA Pediatric Advisory Committee. September 13-14, 2004(a). Online document at: www.fda.gov/ohrms/ dockets/ac/04/minutes/2004-4065M1_Final.htm

U.S. Food and Drug Administration: FDA Launches a multipronged strategy to strengthen safeguards for children treated with antidepressant. October 15, 2004(b). Online document at: www.fda.gov / bbs/topics/news/2004/NEW01124.html

Valuck RJ, Libby AM, Sills MR, Giese AA, Allen RR: Antidepressant treatment and risk of suicide attempt by adolescents with major depressive disorder: A propensity-adjusted retrospective cohort study. CNS Drugs 18:1119-1132, 2004.

Wagner KD, Ambrosini P, Rynn M, Wohlberg C, Yang R, Greenbaum MS, Childress A, Donnelly C, Deas D: Efficacy of sertraline in the treatment of children and adolescents with major depressive disorder: Two randomized, controlled trials. JAMA 290:1033-1041, 2003.

Wagner KD, Robb AS, Findling RL, Jin J, Gutierrez MM, Heydorn WE: A randomized, placebo-controlled trial of citalopram for the treatment of major depression in children and adolescents. Am J Psychiatry 161:1079-1083, 2004.
Weissman MM, Wolk S, Goldstein RB, Moreau D, Adams P, Greenwald S, Klier CM, Ryan ND, Dahl RE, Wickramaratne P: Depressed adolescents grown up. JAMA 281:1707-1713, 1999a.

Weissman MM, Wolk S, Wickramaratne P, Goldstein RB, Adams P, Greenwald S, Ryan ND, Dahl RE, Steinberg D: Children with prepubertal-onset major depressive disorder and anxiety grown up. Arch Gen Psychiatry 56:794-801, 1999b.

Whittington CJ, Kendall T, Fonagy P, Cottrell D, Cotgrove A, Boddington E: Selective serotonin reuptake inhibitors in childhood depression: Systematic review of published versus unpublished data. Lancet 363:1341-1345, 2004.

Whittington CJ, Kendall T, Pilling S: Are the SSRIs and atypical antidepressants safe and effective for children and adolescents? Curr Opin Psychiatry 18:21-25, 2005.

Address reprint requests to: Christopher J. Kratochvil, M.D. 985581 Nebraska Medical Center

Omaha, Nebraska 68198-5581

E-mail: ckratoch@unmc.edu 


\section{This article has been cited by:}

1. Eric M. Parise, Lyonna F. Alcantara, Brandon L. Warren, Katherine N. Wright, Roey Hadad, Omar K. Sial, Kyle G. Kroeck, Sergio D. Iñiguez, Carlos A. Bolaños-Guzmán. 2013. Repeated Ketamine Exposure Induces an Enduring Resilient Phenotype in Adolescent and Adult Rats. Biological Psychiatry 74:10, 750-759. [CrossRef]

2. Robert L. Findling, Adelaide Robb, Anjana Bose. 2013. Escitalopram in the Treatment of Adolescent Depression: A Randomized, Double-Blind, Placebo-Controlled Extension Trial. Journal of Child and Adolescent Psychopharmacology 23:7, 468-480. [Abstract] [Full Text HTML] [Full Text PDF] [Full Text PDF with Links]

3. Nancy Rappaport, Deborah Kulick, LeAdelle Phelps. 2013. PSYCHOTROPIC MEDICATIONS: AN UPDATE FOR SCHOOL PSYCHOLOGISTS. Psychology in the Schools 50:6, 589-600. [CrossRef]

4. Carroll W. Hughes, Shauna Barnes, Conrad Barnes, Laura F. DeFina, Paul Nakonezny, Graham J. Emslie. 2013. Depressed Adolescents Treated with Exercise (DATE): A pilot randomized controlled trial to test feasibility and establish preliminary effect sizes. Mental Health and Physical Activity 6:2, 119-131. [CrossRef]

5. Mary Lynn Dell. 2012. Child and Adolescent Depression: Psychotherapeutic, Ethical, and Related Nonpharmacologic Considerations for General Psychiatrists and Others Who Prescribe. Psychiatric Clinics of North America 35:1, 181-201. [CrossRef]

6. Mary N. Cook, John PetersonAdolescent with depression 518-523. [CrossRef]

7. Sergio D. Iñiguez, Brandon L. Warren, Carlos A. Bolaños-Guzmán. 2010. Short- and Long-Term Functional Consequences of Fluoxetine Exposure During Adolescence in Male Rats. Biological Psychiatry 67:11, 1057-1066. [CrossRef]

8. Zheya Jenny Yu, Christopher J. Kratochvil, Ronald A. Weller, Mira Mooreville, Elizabeth B. Weller. 2010. From TADS and SOFTADS to TORDIA and Beyond: What's New in the Treatment of Adolescent Depression?. Current Psychiatry Reports 12:2, 88-95. [CrossRef]

9. Carroll W. Hughes, Madhukar H. Trivedi, Joseph Cleaver, Tracy L. Greer, Graham J. Emslie, Beth Kennard, Shauna Dorman, Tyson Bain, Judy Dubreuil, Conrad Barnes. 2009. DATE: Depressed adolescents treated with exercise: Study rationale and design for a pilot study. Mental Health and Physical Activity 2:2, 76-85. [CrossRef]

10. David Taylor, Carol Paton, Shitij KapurChildren and adolescents 251-283. [CrossRef]

11. Abbey L. Reed, Jeffrey C. Anderson, David B. Bylund, Frederick Petty, Hesham Refaey, H. Kevin Happe. 2009. Treatment with escitalopram but not desipramine decreases escape latency times in a learned helplessness model using juvenile rats. Psychopharmacology 205:2, 249-259. [CrossRef]

12. Megan F Joseph, Eric A Youngstrom, Jair C Soares. 2009. Antidepressant-coincident mania in children and adolescents treated with selective serotonin reuptake inhibitors. Future Neurology 4:1, 87-102. [CrossRef]

13. Supriya K. Bhatia, Amy J. Rezac, Benedetto Vitiello, Michael A. Sitorius, Bruce A. Buehler, Christopher J. Kratochvil. 2008. Antidepressant Prescribing Practices for the Treatment of Children and Adolescents. Journal of Child and Adolescent Psychopharmacology 18:1, 70-80. [Abstract] [Full Text PDF] [Full Text PDF with Links]

14. Megan E. Kozisek, David Middlemas, David B. Bylund. 2008. The differential regulation of BDNF and TrkB levels in juvenile rats after four days of escitalopram and desipramine treatment. Neuropharmacology 54:2, 251-257. [CrossRef]

15. Günter Seelinger, Marcus Mannel. 2007. Drug Treatment in Juvenile Depression ? Is St. John's Wort a Safe and Effective Alternative?. Child and Adolescent Mental Health 12:3, 143-149. [CrossRef]

16. Angela J. Dean, Anna Hendy, Treasure McGuire. 2007. Antidepressants in children and adolescents—changes in utilisation after safety warnings. Pharmacoepidemiology and Drug Safety 16:9, 1048-1053. [CrossRef]

17. Megan E. Kozisek, Jean D. Deupree, William J. Burke, David B. Bylund. 2007. Appropriate dosing regimens for treating juvenile rats with desipramine for neuropharmacological and behavioral studies. Journal of Neuroscience Methods 163:1, 83-91. [CrossRef]

18. CARROLL W. HUGHES, GRAHAM J. EMSLIE, M. LYNN CRISMON, KELLY POSNER, BORIS BIRMAHER, NEAL RYAN, PETER JENSEN, JOHN CURRY, BENEDETTO VITIELLO, MOLLY LOPEZ, STEVE P. SHON, STEVEN R. PLISZKA, MADHUKAR H. TRIVEDI. 2007. Texas Children's Medication Algorithm Project: Update From Texas Consensus Conference Panel on Medication Treatment of Childhood Major Depressive Disorder. Journal of the American Academy of Child \& Adolescent Psychiatry 46:6, 667-686. [CrossRef]

19. Jörg Michael Fegert, Michael Kölch. 2007. Medikamentöse Therapie der Depression bei Kindern und Jugendlichen. Praxis der Kinderpsychologie und Kinderpsychiatrie 56:3, 224-233. [CrossRef]

20. Lacramioara Spetie, L. Eugene Arnold. 2007. Ethical issues in child psychopharmacology research and practice: emphasis on preschoolers. Psychopharmacology 191:1, 15-26. [CrossRef] 
21. Benedetto Vitiello. 2007. Research in child and adolescent psychopharmacology: recent accomplishments and new challenges. Psychopharmacology 191:1, 5-13. [CrossRef]

22. MICHAEL E. THASE. 2006. Bipolar depression: Diagnostic and treatment considerations. Development and Psychopathology 18:04. . [CrossRef]

23. CHRISTOPHER KRATOCHVIL, GRAHAM EMSLIE, SUSAN SILVA, STEVE McNULTY, JOHN WALKUP, JOHN CURRY, MARK REINECKE, BENEDETTO VITIELLO, PAUL ROHDE, NORA FEENY, CHARLES CASAT, SANJEEV PATHAK, ELIZABETH WELLER, DIANE MAY, TARYN MAYES, MICHELE ROBINS, JOHN MARCH. 2006. Acute Time to Response in the Treatment for Adolescents With Depression Study (TADS). Journal of the American Academy of Child \& Adolescent Psychiatry 45:12, 1412-1418. [CrossRef]

24. Shawn M McClintock, Mustafa M Husain. 2006. Association of suicide in the elderly and SSRI antidepressants: information from a population-based study. Aging Health 2:6, 917-918. [CrossRef]

25. 2006. Current awareness: Pharmacoepidemiology and drug safety. Pharmacoepidemiology and Drug Safety 15:10, i-xii. [CrossRef]

26. Jeff Q. Bostic, Mona P. Patel, Jefferson B. Prince. 2006. Elephants in the Room: Weighing the Benefits vs. the Risks of Antidepressant Treatment in Children. Child and Adolescent Psychopharmacology News 11:4, 1-5. [CrossRef] 